\title{
PHENOL IRRIGATION FOR PILONIDAL SINUS
}

\author{
Lieutenant-Colonel M. S. OWEN-SMITH, M.S., F.R.C.S., R.A.M.C.
}

ANZUK Military Hospital, Singapore

SUMMARY: A technique is described of treating pilonidal sinus by irrigation of the sinus with pure phenol, this is followed by the use of a depilatory cream and specific hygiene measures to maintain the area clean and free from hair. This technique is painless, is simple to do once it has been mastered, is associated with a short period in hospital and the patient's immediate return to work. The results of 32 cases over a period of eight years are given. The adoption of the technique is advocated, and its use in the prophylactic irrigation of symptomless post-anal sinuses is proposed.

\section{Introduction}

In 1833 Mayo described the case of a young man with a hair-containing sinus in the sacrococcygeal region, this was treated by laying the sinus open and allowing it to granulate. Anderson (1847) described his successful treatment of an infected post-anal sinus by simple incision and extraction of the hairs from its cavity. Hodges (1880) wrote of a similar condition which he called " pilonidal sinus disease" because hairs were a common finding in the sinuses of patients with such a lesion.

Pilonidal sinuses may occur in a number of situations but it is the post-anal variety which occurs most frequently, and to which the term pilonidal sinus usually applies. In this condition there is a sinus in the midline of the gluteal cleft approximately $5 \mathrm{~cm}$ from the anal verge. The sinuses may be single or multiple, they vary in size from being very tiny up to 2 to $3 \mathrm{~mm}$ in diameter and the sinus usually passes in a cephalad direction. The mouth of the sinus is smooth and the track is lined with squamous epithelium for the first few millimetres, the track usually leads into a cavity in the subcutaneous tissue which is lined by granulations and which contains hair and debris. The tracks may branch in different directions away from the midline and when subcutaneous abscesses are formed they may discharge spontaneously to the exterior leaving a fistulous opening lined by granulation tissue and discharging pus. The diagnosis presents little problem. Symptoms of a tender lump at the base of the spine often associated with discharge, together with the presence of a midline sinus which is constant in position and with an associated subcutaneous abscess forms a well recognised clinical entitv

\section{Incidence}

Approximately 1 per 1,000 hospital admissions are for pilonidal sinus disease (Kooistra 1942). There is a rapid increase in the incidence at the age of 17 years, a peak is reached at the age of 19 to 25 years and 60 per cent of all presentations occur in this age bracket. Approximately three quarters of the patients are males. Racial incidence is interesting in that it almost always occurs in those of Caucasian origin. It has been occasionally reported in Negroes but hardly ever in the yellow, brown or red skinned races. It occurs typically in men with stiff, curly body hair but it also occurs in those people with fair hair and in females with very little body hair. 


\section{Aetiology}

Ever since the first descriptions of the disease there have been arguments as to whether the condition is congenital or acquired. Patey (1969) believed that a synthesis of the facts known on post-anal pilonidal sinus could be made to provide a very good basis for the acquired theory of origin. First a sinus is formed in the midline of the gluteal cleft approximately $5 \mathrm{~cm}$ from the anal verge. A few sinuses in this region may be congenital but the majority are probably acquired in the following way. The skin in the gluteal cleft at a distance of $5 \mathrm{~cm}$ from the anal verge is the point at which the skin is tacked down to the underlying sacrococcygeal junction by fascial bands (Klass 1956). It is the most immobile part of the skin in this region. Brearley (1955) showed that the movements of the buttocks on walking, or particularly on sitting, create local pressure changes. The pressure exerted by lateral traction of the flat surface of the buttocks on either sides of the gluteal cleft was of the order of $80 \mathrm{~mm}$ of water. Hair follicles exist in the midline of the gluteal cleft, and if the hair of the follicle was shed following some minor inflammatory episode this would result in the formation of a small epithelial lined pit. The hair follicles in patients with a pilonidal sinus are commonly up to $6 \mathrm{~mm}$ deep (Weale 1955). Lateral traction would cause the pit to become enlarged and thus a pit 5 to $6 \mathrm{~mm}$ in depth would be formed. Hair which is broken off from the patient's head, back or buttocks is channelled by the movements of clothes into the upper end of the gluteal cleft and the hair comes to lie longitudinally in the base of the cleft. Patey and Scarff (1955) followed up the suggestion of one of their students, E. S. Williams, who reminded them of the trick of making a head of barley migrate up a person's coat sleeve by introducing the head of barley into the sleeve, base first. They discovered that the mechanism of propulsion of hair is the same. Scales of hair are so arranged that their free ends point peripherally. As a result, if the hair is stroked along its surface from root to periphery there is little movement of the hair. If however the hair is stroked from the periphery towards the root then the hair scales catch and the hair is propelled in the direction of the root. This can be clearly shown by taking a hair and rolling it between the thumb and finger when it will be seen to proceed rapidly in one direction, that direction being towards the root of the hair. Thus hairs lying in the gluteal cleft will be moved by the pressure forces created by the movements of the buttocks. The hairs will move according to the direction of the scales in a cephalad or caudad direction. If the hairs enter the sinus root first the same forces will drive them into the depths of the sinus. The hairs take with them epithelial debris and bacteria creating a subcutaneous cavity with subsequent infection, possible abscess and secondary fistula formation. Proof of this mode of action was clearly demonstrated by Page in 1969. A patient of his had two pilonidal sinuses. He put hair from the same patient into each sinus, one root first and the other, which was marked, point first. The patient was then allowed to get up and walk around. On review the hair with the root placed inside the mouth of the sinus had been completely drawn in, whereas the other hair with the tip placed in the sinus was still lying loosely. Hair is commonly seen to be protruding from a pilonidal sinus and whenever this is carefully removed and examined it will be found that they all entered the sinus base first. Ninety per cent of secondary tracking occurs from the midline sinus in a cephalad or lateral and cephalad direction (Notaras 1970, Millar 1970). Millar suggested that this did not occur by chance, and by the use of hair direction charts showed that the direction of hair follicles in the natal cleft area was directly related to the direction of the secondary tracking. All secondary tracks from a pilonidal sinus run 
in the direction of the local hair follicles. He claimed that this supported the theory that the primary pit in pilonidal sinus disease is a pilo-sebaceous follicle from which the hair has been shed. He believed that the difference in mobility of the natal cleft would account for the sex difference found in post-natal pilonidal disease in adults.

Pilonidal sinuses with the same aetiology have been described in the suprapubic region (McLeod 1953, Patey and Currey 1962, Crosby 1962). They have only occurred in this region in women and this was thought to be due to the trough effect of the vulva which allowed hairs to be aligned along its depths. These hairs could then penetrate a sinus developed from a pilo-sebaceous follicle once the necessary pressures were applied. It has also been described at the umbilicus by Patey and Williams (1956). In this case they removed the tuft of hairs and noted that they were all root first in the sinus. They showed the sinus was extended into a subcutaneous cavity in which hairs were placed with their bases away from the sinus. They took this as further proof of the acquired nature of pilonidal sinuses in general.

Pilonidal sinuses have also been described in the axilla (Ewing 1947, Smith 1948, Aird 1952) and in the hands of barbers (Ewing 1947, Patey and Scarff 1948) and on the hands of sheep shearers (King 1949, Matheson 1951). Pilonidal abscesses of the axilla, perineum and hands are, I believe, of a different aetiology in that this involves cut hair. The cut hair has a sharp edge and can penetrate the intact skin. It is common for barbers to pick cut hair out of the webs of their fingers after cutting a client's hair. The same would apply to the cut wool from the sheep, and Hodges (1880) reported that the removal of hairs from beneath the skin of the feet was a practice repeatedly performed by "pedicures".

\section{Treatment}

The early lesion may sometimes be treated successfully without operation. Hardaway (1958) showed that the admission rate to American Army Hospitals in 1944 was 3 per 1,000 and in 1953 it was 3.24 per 1,000. In Germany he used more conservative measures which involved regular shaving and thorough cleansing of the area, attention to sitting posture and change of duty, if possible, He reserved operation only for those in whom the regime failed. He was able to reduce the hospital admission rate to 1 per 1,000 in 1956 with an average stay in hospital of 6.6 days. Brearley (1955) recommended regular scrubbing of the area to remove hairs from the small, 'early lesions. Various operative procedures have been used in the treatment of the established condition. Simple incision followed by either primary suture or allowing the wound to granulate (Buie 1938) is a treatment which in most people's hands carries a high recurrence rate although Rickles (1961) in a series of over 100 patients claimed that he had no true recurrence. Excision of the sinus followed by various procedures is probably the most popular form of treatment at the present. After excision the wound may be packed and left open to granulate, this usually takes 5 to 6 weeks to heal. After excision the wound may be sutured primarily, usually with some technique to produce pressure on the wound in order to prevent haematoma formation and promote primary healing. The wound may be closed by Z-plasty technique (Monro and McDermott 1965) or use of a lumbar flap (Davies and Starr 1945) or by performing a split skin graft to the defect (Lahey 1929). Lord and Millar (1965) described their technique whereby they excised a midline strip of skin containing the sinus and removal of all hairs and debris from the secondary tracks by fine brushes. The advantage claimed of this treatment was the early discharge 
from hospital and a complication or recurrence rate at least equivalent to most other methods. Whatever the procedure used experience shows that it is commonly associated with a prolonged period of hospitalisation and of time away from the patient's work. Oldham in 1941 showed that the time to heal by granulation averaged three months. Goodall in 1961 showed that the patients averaged 13 weeks off work and Notaras (1970) following up patients treated at St. Mark's Hospital by three different techniques were in hospital for 2 to 4 weeks and away from work for 6 to 8 weeks. Some authors, such as Stevenson (1959), Rickles (1961) and Swinton \& Roe (1964) claim no recurrence whatsoever. Other authors using the same technique show complications and late recurrences ranging from 3 to 20 per cent. Notaras (1970) showed that the late recurrence for all three major techniques were approximately 10 per cent and this figure probably reflects the overall results that the majority of surgeons countrywide would obtain.

The key to successful operative treatment of this condition lies not in the magic of one particular operative procedure but rather more in meticulous attention to detail in the performance of any one of a number of procedures. Those authors who claim excellent results all stress the point that they exercise the greatest care in the performance of the operation which they advocate and also in the postoperative care and follow-up of the patient. This is the real reason for the quality of their results as compared to those who take a more casual attitude and look on pilonidal sinus disease as a common condition to be left to the care of their inexperienced juniors. If good results can be achieved by any one of several operations which one should be chosen? From the operation point of view the choice would seem to be between:--

a. Excision and primary suture. $b$. Excision and allowing the wound to granulate. c. Incision and allowing the wound to granulate.

On the grounds of comfort and convenience for the patient together with the most economical use of hospital beds excision of the sinus with primary suture is the preferable procedure for most patients.

\section{Injection treatment of sinuses}

Crookhall (1927) appears to be the first to attempt to inject a pilonidal sinus and he used caustic silver nitrate. Anderson (1931) tried the use of chloride of mercury. Cutler and Zollinger (1933) applied Carnoy's fluid (which is a sclerosing solution) after the excision of the sinus, but in one case they actually injected the fluid after curetting the sinus and obtained primary healing. Similarly Biegelson (1939) applied Carnoy's fluid to two cases after laying the sinus open. He also injected one sinus after curetting and followed this by the application of Nitric acid on a needle.

Maurice and Greenwood (1964) described a series of over 100 patients with pilonidal sinus disease treated by operation with a 12 per cent recurrence rate and an average stay in hospital of three weeks. They felt that if the epithelial and granulation lined subcutaneous tracks could be destroyed then this would result in healing of the pilonidal sinus. The method whereby phenol was injected prior to laying the wound track 'open and allowing to granulate had already been described by Mimpriss (1961). They proceeded to develop a technique for irrigation of the pilonidal sinus with pure phenol and showed the results in 21 cases-14 male and 7 female-of whom 10 had received previous treatment. Seventeen of the patients were completely cured with an average hospital stay of 36 hours. Four patients needed subsequent surgery and of these three had 
abscesses which were thought to be due to extravasation of phenol - a fault in the technique used. These results were comparable to those obtained by surgery and involved a simple overnight stay in hospital. In 1968 Stephens and Sloane used the same technique on 20 patients in Sydney. All the patients were discharged from hospital on the day after the procedure. Eighteen were completely cured in the follow-up time ranging from three months to two years. In two cases there was an inflammatory reaction around the sinus area and a small slough developed which was treated conservatively and healed completely in 3 to 4 weeks. They again felt that these two cases were due to extravasation of phenol by a fault in the technique. They also noticed that when healing occurred the sinus was completely obliterated. They stress the careful follow-up of these patients and that the area was kept completely clear of hair by using a depilatory cream.

\section{Technique}

Intubation and general anaesthesia is used and the patient is placed prone on the operating table in a slightly jack-knife position so that the sacroccygeal area is horizontal. The area is thoroughly cleansed and shaved and the buttocks are strapped gently apart with elastoplast strapping. Any hair in the sinus track is removed with forceps and then the skin surrounding the area is protected with petroleum jelly and a swab, covered with petroleum jelly, is tucked firmly against the anus to protect it (Fig. 1). The area is then towelled off and the actual sinus cleared with a probe. The surgeon

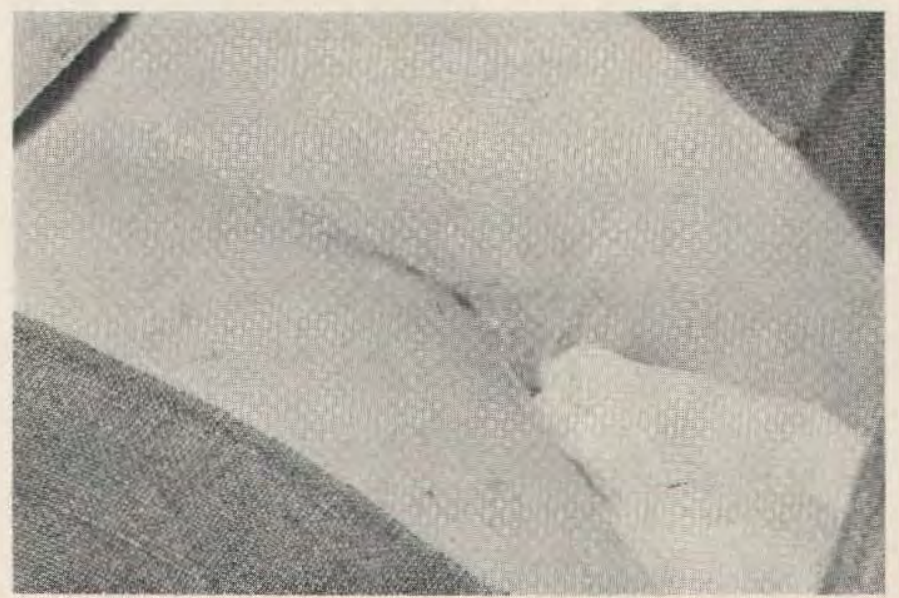

Fig. 1. Skin around the pilonidal sinus protected with petroleum jelly.

is gowned and gloved and also wears a protective eye shield and the remainder of the theatre team keep clear of the operation area. This is to protect the surgeon and the spectators in case there is an inadvertent leak of phenol. Pure phenol is then drawn up into an all glass syringe and the syringe is attached to a blunt needle. A series of stainless steel needles of different diameters must be available and kept solely for this purpose. Their pointed ends must be removed and the blunt end so formed carefully rounded with a file. This is very important as there must be no penetration of the tissues around the actual sinus by the needle. The needle is then carefully inserted into the sinus and the Phenol gently injected until the sinus is full and begins to overflow. This usually involves 
1 to $2 \mathrm{ml}$ of phenol. The needle is then removed and the excess Phenol absorbed with a swab. The phenol is allowed to be in contact with the sinus for a minute and with one finger over the sinus the surrounding tissues are gently massaged to allow the phenol to flow to all parts of the subcutaneous cavity. Pressure is then applied to the area to squeeze the phenol and debris out from the sinus opening. This procedure is repeated three or four times and usually after the first time there will be an increasing flow of debris and finally the ejection of hair (Figs 2 and 3). The procedure of irrigation, massage

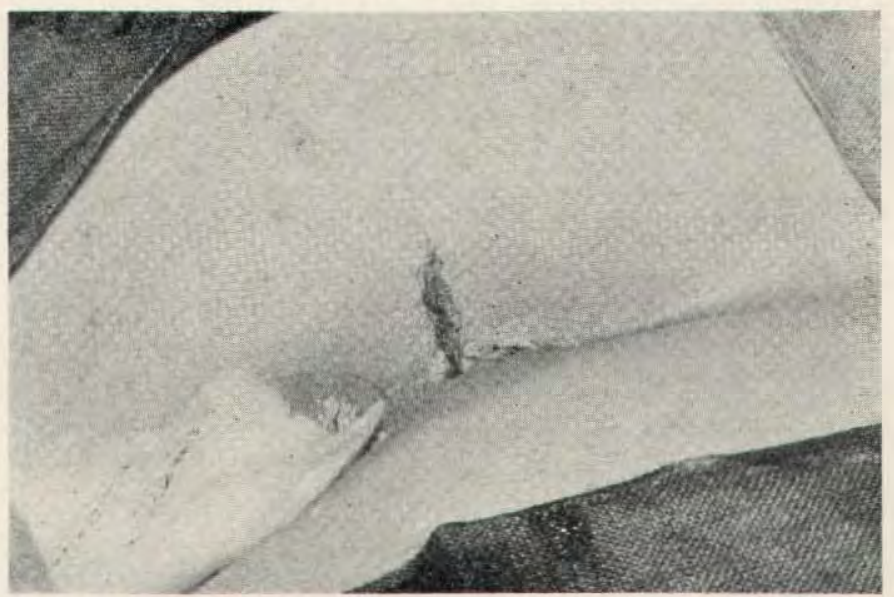

Fig. 2. After irrigation with phenol, some hair has been expressed from the sinus.

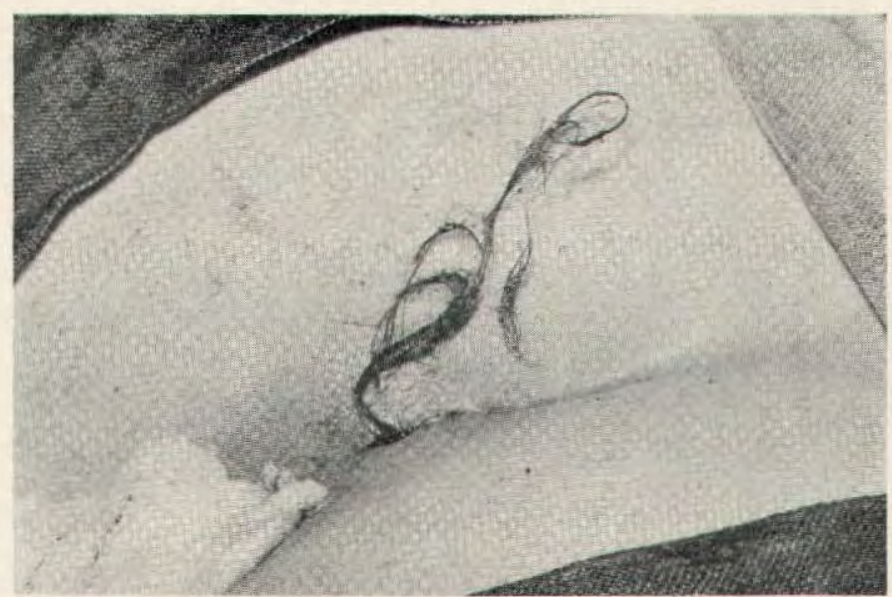

Fig. 3. The expression of hair and debris has been nearly completed.

and then removal of the debris must be repeated until there is no further flow of debris and hair. This procedure must be done with great care and the surgeon must be gentle at all times. It is most important that the needle never penetrates normal tissue and that he persists until all debris has been irrigated and expressed. He may well require to apply more petroleum jelly to the skin. The sinus opening now usually blanches white 
and if there is any slight spillage onto the skin this will also go white. Finally a dry dressing is applied and the patient allowed to recover. He is discharged from hospital the next day with instructions to have twice daily baths and to apply a dry dressing as long as there is any discharge. He is seen at follow-up at regular intervals. The usual findings are that the mouth of the sinus becomes inflamed, the discharge ceases within a few days and 2 to 3 weeks later when the area is inspected it is usually completely healed with no sign at all of the midline sinus. The patient is instructed to keep the area as clean as possible. He must have daily baths and scrub the area with soap and water, and he must keep the whole area clear of hair by using a depilatory cream every three weeks.

\section{Results}

Thirty-two patients have been treated over a period of eight years. There were 28 males and four females. Five were civilians. The rest were personnel from British, Australian and New Zealand services. All were followed up for a minimum of five months with three exceptions. Two of these were seen after a month before rejoining their ships and one for three months before returning to Australia. The longest follow-up has been for eight years.

Thirty patients were discharged from hospital within two days. Most of these on the day following operation. Two patients developed localised areas of necrosis and were treated by Eusol packs for about ten days before discharge. All discharged patients were returned to light duties immediately and most were able to resume their full duties after a week.

No patient complained that the procedure was painful. They felt there were no problems in applying dry dressings for the first few days until the discharge from the treated sinus had dried up.

In a few cases, antibiotics had been prescribed by the patients' own doctors because of some localised tenderness and erythema. They were not used routinely.

No recurrence have been detected at follow-up. The skin in the base of the gluteal cleft presents a smooth, unpitted surface.

\section{Discussion}

The Services in general and the Army in particular lose a large number of man days due to pilonidal sinus disease. In the British Army the latest available figures are for 1972. As a result of pilonidal sinus disease 117 patients were admitted to hospital with an average stay of 22 days, and time away from duty of over four weeks. There were 3,305 lost man days. Hardaway (1958) said that 77,637 soldiers were admitted to United States Army hospitals in 1942 to 1945 for pilonidal sinus disease. Hospital admission rates were 3.05 per thousand and the average stay was 43 days. Buie and Curtis (1952) quoted Pugh (1952) to show that from 1944 to 1951 the United States Army lost 530,701 man days and in 1947 to 1950 over 1,800 operations per year were performed for this condition. In French Military hospitals Favre and Delacroix (1964) reported 500 operations per year for pilonidal sinus disease.

The condition is treated by different surgeons using a number of different techniques but the one common result is that the treatment is usually associated with a prolonged period of hospitalisation. This report has shown that the results of irrigation of pilonidal 
sinus by phenol give results which are equal to the best results obtained using surgical techniques. However there is one particular advantage using the irrigation technique which is of great importance to the Army and that is that the patient need only be in hospital for two days and can then be returned to light duties straight away and to full duties within a week. The adoption of this technique would reduce the total number of man days spent in hospital for this condition.

A further consideration is that there are probably many symptomless sinuses existing in the post-anal region and these will later on become infected and will present for treatment. I believe that all recruits should be examined specifically for this condition and also that at routine PULHEEMS examinations the sinus should be specifically looked for. If such sinuses are present they should be removed by irrigation with phenol in order to prevent the development of pilonidal sinus disease.

The institution of prophylactic treatment of sinuses by irrigation before they cause symptoms, together with the treatment of pilonidal sinuses when they first present by irrigation with phenol would result in a decrease in the number of admissions to hospital and in the total number of man days lost to the Army for treatment of pilonidal sinus disease.

\section{REFERENCES}

AIRD, I. (1952). Brit. med. J. i, 903.

ANDERSON, A. W. (1847). Boston med. surg. J. 36, 74.

Anderson, J. K. (1931). Minn. Med. 14, 421.

Biegelson, H. I. (1939). Amer. J. Surg. 44, 622.

Brearify, R. (1955). Brit. J. Surg. 43, 62.

Bute, L. A. (1938). Practical Proctology. Saunders. Philadelphia.

Buit, L. A. and Curtis, R. K. (1952). Surg. Clin. N. Amer. 32, 1247.

Crookall, A. (1927). Trans. Amer, proctol. Soc. 28, 32.

Crosby, D. L. (1962). Brit. J. Surg, 49, 457.

Cutler, E. C. and Zollinger, R. (1933). Amer. J. Surg. 19, 411.

Davies, L. S. and Starr, K. W. (1945). Surg. Gynec. Obstet. 81, 309.

EWING, M. R. (1947). Lancet, i, 427.

Favre, R. and Delacroix, P. (1964). Mem. Acad. Chir. 90, 669.

Goodall, P. (1961). Brit. J. Surg. 49, 212.

Hardaway, R. M. (1958). Arch, Surg. 74, 143.

Hodges, R. M. (1880). Boston med. Surg. J. 103, 485.

KING, E. S. J. (1949). Aust. N. Z. J. Surg. 19, 29.

Klass, A. A. (1956). Can. med. Ass. J. 75, 737.

Kooistra, H. P. (1942). Amer. J. Surg. 55, 3.

LAHEY. F. H. (1929). Surg. Gynec. Obstet. 48, 109.

Lord, P. H. and Millar, D. J. (1965). Brit. J. Surg, 42, 4.

MacLoed, R. G. (1953). Brit. med. J. i, 710.

Matheson, A. D. (1951). Aust. N. Z. J. Surg. 21, 76.

Maurice, B. A. and Greenwood, R. K. (1964). Brit. J. Surg. 51, 510.

Mayo, H. (1833). Observations on Injuries and Diseases of the Rectum. Burgess \& Hill. London. P. 45.

Millar, D. M. (1970). Proc. roy, Soc. Med. 63, 1263.

Mimpress, T. W. (1961). Brit. J. Urol. 33, 167.

Monro, R. S. and McDermott, F. T. (1965). Brit. J. Surg. 52, 177.

Notaras, M. J. (1970). Brit. J. Surg. 57, 886.

Oldham, J. B. (1941). J. roy. nav. med. Serv. 27, 34.

Page, G. H. (1969). Brit. J. Surg. 56, 32.

PATEY, D. H. (1969). Brit. J. Surg. 56, 463.

PATEY, D. H. and CURRY, R. C. (1962). Lancet i, 620.

PATEY, D. H. and SCARFF, R. W. (1948). Lancet ii, 13.

PATEY, D. H. and SCARFF, R. W. (1955). Lancet i, 772 .

Patey, D. and Williams, E. S. (1956). Lancet ii, 281.

RickLes, J. A. (1961). J. int. Coll. Surg, 36, 71.

Sмiтн, T. E. (1948). J. Amer. med. Ass. 136, 973.

Stephens, F. O. and SlonNe, D. R. (1968). Med. J. Aust. 4, 395.

Stevenson, D. L. (1959). Brit. med. J. ii, 430.

Swinton, N. W. and Rowe, W. (1964). Surg. Clin. N. Amer. 44, 859.

WEALE, F. E. (1955), Lancet i, 230. 